\title{
The University of Michigan Library Espresso Book Machine Experience
}

by Terri Geitgey

\begin{abstract}
Purpose - The purpose of this paper is to describe one university library's use of the Espresso Book Machine ${ }^{\circledR}(E B M)$, an innovative publishing technology that provides new options for matching content delivery to user needs. The paper aims to provide insight into the University of Michigan Library's experience with version 1.5 of this patented, integrated machine that automates the printing, binding, and trimming of softcover books from digital files.

Design/methodology - The paper describes the machine's technology, the Library's impetus for purchase, services currently offered and plans for future uses, as well as advantages and challenges of owning a machine.

Findings - Although relatively new and still undergoing refinement, the Espresso Book Machine ${ }^{\circledR}$ technology can add value to library services by providing high quality, cost effective print options not otherwise available to the campus community and beyond. Specific advantages include speed, flexibility, access to networked content, and low-cost output. Improvements by On Demand Books to the search and display capabilities of the EspressNet catalog will be needed in order to maximize the catalog's usefulness.

Research limitations/implications - Apart from a brief discussion of an article published about the University of Utah's Marriott Library experience, the paper does not include a survey or report of other EBM-owning institutions and ways the machines are being used at those locations. Experiences may vary among EBM owners based on a number of factors.

Value - Other academic institutions considering the purchase of an EBM may benefit from an in-depth report of the University of Michigan's experience.
\end{abstract}

\section{Introduction}

In June of 2008, the lobby of the Shapiro Undergraduate Library at the University of Michigan became home to a version 1.5 Espresso Book Machine ${ }^{\circledR}$, or "EBM", a patented machine that automatically produces printed, bound, and trimmed softcover books from digital files. At that time, it was the first EBM to be installed in a university library in the U.S., and only the seventh such machine installed anywhere in the world. Since then, On Demand Books, LLC (ODB), the company that manufactures and sells the EBM, has introduced a subsequent generation of the machine (version 2) and expanded its services and partnerships in its continuing effort to market the machines, offer more content, and broaden their appeal. As of this writing, there are currently $40 \mathrm{EBMs}$ in libraries and bookstores around the world, including Australia, China, Japan, Egypt, the United Arab Emirates, the U.K., Canada, and the U.S. Roughly fifteen of those reside in university bookstores, four in university libraries, five in public libraries (including 
three machines in Egypt's Library of Alexandria), and sixteen in independent commercial bookstores. [1]

The Espresso Book Machine ${ }^{\circledR}$ has the potential to be a transformative publishing and distribution technology that can put small and independent bookstores on a more even footing with big box chains, since shelf space for physical books becomes irrelevant; it provides the perfect mechanism for tapping into the Long Tail concept of selling few copies of many obscure books, rather than many copies of a limited number of popular titles; its global network allows the ability to offer content customized for geographical markets, and it removes the boundaries of physical access to books held in library collections by making hundreds of thousands of titles available to any location in the world that has a machine. It also eliminates the traditional publishing model's need for physical book transportation, storage, and pulping of overstock.

\section{Background}

For years, the University of Michigan Library has been digitizing public domain books from its considerable holdings and making them available online in various electronic collections such as The Making of America (MOA) (http://quod.lib.umich.edu/m/moagrp/) and The Historical Mathematics Collection (http://quod.lib.umich.edu/u/umhistmath/). Much of this digitization work was undertaken as part of a brittle books reformatting program, in an effort to capture page images of aging books printed on acidic paper before the print volumes deteriorated beyond use.

Through its partnership with Google, Michigan's already large corpus of electronic content is growing at an incredible pace, resulting in a vast, rich digital repository with all the advantages electronic texts afford, such as full-text searching, downloadable page images, full text display of public domain titles, personal collection building, and 24/7 online access from anywhere in the world.

As wonderful as that resource is, sometimes a good old-fashioned physical book is what people want. In fact, the Library's six year old print on demand (POD) program was created largely in response to user requests to purchase print copies of the electronic texts in the public domain online collections such as MOA. On Demand Books contacted the University in 2007 to introduce their revolutionary book-making machine and discuss how it might fit with the Library's large-scale digitization efforts. Having an Espresso Book Machine ${ }^{\circledR}$ on site seemed like the perfect tool to match content format to user needs, on demand and at point of sale, allowing the Library to take immediate advantage of the reprint potential inherent in the hundreds of thousands of public domain files residing in the Library's repository.

Intrigued by the machine's potential, and willing to experiment with a new technology that could provide a valuable service to the University community and beyond, Library Administration sanctioned the idea and placed "an Espresso Book Machine ${ }^{\circledR}$ on the annual Library donor wish list. The response was overwhelming and gratifying. It seemed Library donors were as excited about the new book machine as the Library itself, and thanks to their generous support, the Library raised the necessary funds to purchase an EBM. 


\section{A Description of the Technology}

Version 1.5 is basically a prototype machine, and looks every bit the part, from its innards of wires and metal clamps and hydraulics visible through the clear Plexiglas ${ }^{\circledR}$ panels that enclose it, to the hissing and clunking sounds produced as it goes about its business of making books. In approximately seven minutes, out drops a trimmed, perfect-bound book with a 4-color cover, still warm and very close in quality to traditionally-produced books.

Considering the EBM's rather remarkable capabilities, consumables for the version 1.5 machine are surprisingly ordinary $-81 / 2$ " $\times 11^{\prime \prime}$ reams of paper (minimum of $20 \#$ ), black and color toner cartridges for the laser printers, $11^{\prime \prime} \times 17$ " sheets of cover stock, and glue pellets ordered directly from the manufacturer. The book block prints on a regular Kyocera black and white laser printer, and the 4-color cover prints on a Konica Minolta color laser printer. Heavier weight paper and cover stock can be used if desired. For example, several books have been printed on high-quality acid-free paper as replacement copies for the collection. The Library strives to keep its EBM-related costs (and therefore, book prices) as low as possible, so for most jobs, paper similar to the 20\# paper found in copiers and printers throughout the Library is used.

In order to print a public domain book from Michigan's collection, the page-scan files must be copied from the server and reformatted into a book block PDF. A cover PDF is also produced after calculating the overall dimensions based on trim size and page count. Initially, the Library programmer working with the EBM developed a process that could automate the creation of book block and cover PDFs, but the output was unreliable due to inconsistencies with the metadata and the page scan files.

Some generic cover background patterns and images were developed to speed the process, and a decision was made to use the title page image on the front cover of each book, both for convenience and for making clear that the book is a reprint of the original pre-1923 title. Fortunately, books printed from ODB's recently-released EspressNet catalog have the advantage of pre-made book blocks and covers, so there is no manual file prep work involved in printing an EspressNet title.

Local files are uploaded via a simple catalog interface, after entering basic metadata such as the book's title, author, trim size, and any comments or notes. The files load within seconds, and are immediately processed by the software, which checks page count and trim sizes and alerts the user to any problems by highlighting the catalog entry in red. The programmer has access to the machine's log files, which display information about file processing and any problems encountered. Once processing is completed, the software generates a thumbnail image of the cover that displays next to the book's title and author information in the local catalog. Files can be deleted from the machine whenever desired.

The software also includes tabs to track the printing history, display the job queue, and access the EspressNet catalog. The operator interface includes numerous buttons to control specific components of the machine, such as the carriage positions and actions, shear actions, jogger, and accumulator clamp. The operator can also suspend or cancel any job in the queue. In 
addition to the on-site operator controls, certain settings and parts of the machine can be tweaked remotely by ODB's technical staff.

Once a book loads successfully, the EBM operator simply clicks an "order" button next to the title in the catalog to begin the production process. The book block or interior pages immediately begin printing on the black and white laser printer, double-sided, last page first. As the pages are printed, they collect in an accumulator tray. While the interior pages are printing, the color cover prints and is conveyed face-down onto the binding table, where it awaits the book block.

After the interior pages finish printing, the stack turns on its side and drops vertically down to a clamp that holds the pages together as it moves through the machine. The edges of the book block (i.e., the spine) are milled or roughed up in order to allow the glue to adhere better, and then passes over a vacuum brush that cleans away any paper dust or loose bits. The book block then travels horizontally so that glue is applied to the spine as it passes over the glue pot wheel, and comes to rest on the cover sheet. The sides of the cover are folded up to surround the book block and clamped tightly to help the cover adhere to the glued spine.

In the last phase, the untrimmed book drops into another clamp and is rotated right-side up and held while the shear blade trims the bottom edge of the book, then rotates the book a quarter turn so that the fore edge can be trimmed, and finally rotates another quarter turn to trim the top edge. Once released, the book slides down a chute to exit the machine, and the trimmed paper scraps fall into a bin under the machine which is emptied periodically for recycling.

The version 1.5 machine can bind a stated minimum page count of 40 and a maximum page count of 550 in a single volume, although Michigan's experience has been that books with fewer than 60 pages or so can be difficult to bind successfully unless heavier-weight paper is used (and sometimes not even then), and that books with more than roughly 450 pages overflow the accumulator tray and require manual intervention (i.e., physically removing the overflow pages until the book has finished printing, and then putting the book block back together before it continues through the process). The PDF files for any books over 500 pages must be split into two smaller volumes. The machine can produce any trim size between $4.5^{\prime \prime} \mathrm{x}$ $4.5^{\prime \prime}$ and 8.25" $\times 10.5^{\prime \prime}$, although higher page counts reduce the maximum trim size in proportion to spine width. Interior pages are limited to black and white only, but the cover printer can produce 4-color covers.

In addition to the local material available, the machines are networked to an extensive and growing "catalog of catalogs" via the machine's EspressNet software. The EspressNet catalog contains content from many sources, including Lightning Source, Google Books, and the Internet Archive. All content either is in the public domain, or the rights holders have specifically permitted its inclusion in the catalog. The machine's software keeps track of books printed from the networked catalog, and On Demand Books collects a portion of the sales amount as fees and royalties that it distributes to the corresponding rights holders. At this time, 
the University of Michigan Library restricts its EspressNet offerings to the Google public domain titles, but will likely begin selling the in-copyright works in the near future as well.

Prices for books from the Library's local EBM catalog currently are set at $\$ 6.00$ for books 150 pages or less, and $\$ 10.00$ for books between 151 and approximately 450 pages. These prices are based on operating costs, including consumables and staff time, with a very modest profit built in. Books in the EspressNet catalog have suggested retail prices set by the individual content providers.

\section{What It's Not}

More than one person has assumed incorrectly that the machine actually scans physical books in order to reprint them. The machines have no scanning capabilities; any books to be printed must already be in digital form - specifically, in PDF format. Others have been surprised to discover that the EBM actually produces "real" perfectbound and trimmed books, expecting instead as one visitor put it, "a bunch of photocopied pages stapled together."

Another common misconception seems to be that any book can be printed on the machine, regardless of copyright status. Quite a few requests have come in for recently published, incopyright titles. The online request form the Library developed attempts to head off at least some of those inquiries by requiring the customer to first enter the publication date of the book they're requesting. One of three automated responses displays based on that date: the request can be filled; the request cannot be filled due to copyright restrictions; or the request may be able to be filled, but copyright status will first need to be ascertained. If a requested title falls into this latter category, librarians in Technical Services research copyright renewal status and the book is printed (or not), accordingly.

Although the EBM is sometimes referred to as an "ATM for books", that depiction is somewhat misleading. The EBM provides no point-of-sale e-commerce mechanism; in other words, there is no provision for processing credit cards or taking payment in any form. It is up to each EBM location to arrange a method of payment. At the University of Michigan, customers are directed to the Shapiro Library's circulation desk to pay for and pick up their books. Payment is collected after the book is printed, not before. The main reason for this is that occasionally, a book may prove impossible to print, or may have other problems such as missing pages or illegible text. It is simpler to collect payment once the book has successfully printed than to deal with processing refunds for orders that ultimately could not be filled. Only a small handful of customers have placed an order and then never picked up and paid for their books, so there is no immediate pressure to change this system.

\section{Library vs. Bookstore}

"Libraries/Universities: The EBM enhances the academic experience for students, makes more books available to more patrons, provides new forms of revenue, and allows you to print your digital collections and create facsimiles of rare books." [2] 
Given that bookstores sell books, while libraries lend them, one might well wonder why a library would want to install a book-making machine and sell books on site. Because the University of Michigan Library already had a well-established print-on-demand program in place offering softcover and hardcover editions of public domain works through printer/distributors such as Lightning Source and BookSurge (now CreateSpace), bringing an EBM into the Library was perhaps a less foreign concept for Michigan than it might be for most academic libraries. The Library was already selling reprints of its titles via Amazon.com, so selling them from an EBM seemed a natural complement to that POD service. But libraries are not limited to using the machine strictly for printing and selling books to the public; as a book-making tool, the machine can be used to print low-cost copies for the stacks, either to replace lost volumes or to add new titles to the collection. It can be used to print internal reference documents and reports, or to produce copies of the proceedings of University-sponsored conferences. It can quickly produce sample or gift copies for visitors or to distribute at special events, and in many cases the broad scope of digitized materials available allows the content of those gift books to be targeted to very specific interests or audiences. The Inter-Library Loan (ILL) department could offer a borrowing institution the option to borrow and return an existing print copy of a public domain title, or to purchase a reasonably-priced EBM version to own outright.

Another appealing aspect of a book-making machine is that it can help reduce students' significant outlay of cash for textbooks and literature classics for their courses. An excellent example is the Library's collaboration with a School of Information professor who remixed open source content about Python programming to produce an introductory book on the topic for his SI502 class. The professor plans to update and expand the book each semester, building on the student feedback of the previous semester's class. The book can be revised and printed in just a few days' time, with a final purchase price to students of only $\$ 10.00$. A base inventory of about $60-75$ copies is usually printed just prior to the start of the semester, and if demand exceeds the stock, more copies can be produced within minutes. As Professor Severance noted,

...creating an open book with a Creative Commons license and printing the book on the EBM allows an amazing collaboration between teachers and students in the creation of shared educational materials. Using the EBM allows the book to be a live document and to be updated every single semester. This allows new material to be developed, used, and edited in one semester and then be part of the printed textbook for the next semester a few weeks later. Another advantage of an EBM book is its low cost - students like that. [3]

\section{Services - Current and Future}

After the machine arrived, a management team comprised of representatives from several Library departments including the Finance Office, User Services, Collection Development, and Publishing was formed to guide policy decisions and begin developing services and procedures. Staff from Library Core Services were also involved in setting up the router and keeping the Linux operating system up to date. [4] 
During an initial four-month testing period, staff worked to become familiar with the machine's operation, experimented with methods for preparing book block and cover files, and dealt with router problems, cover printer issues, and general machine glitches.

Because staff time and resources were limited, the services connected with the EBM have grown rather slowly. The Library planned to implement the offerings gradually, beginning with the foundational service of supplying students, faculty, staff, and the general public with fast, cost-effective reprints of public domain titles from digital collections. The initial modest local catalog was made available for browsing (http://www.lib.umich.edu/espresso-bookmachine/reprints), a basic web site was developed (http://www.lib.umich.edu/espresso-bookmachine), and an online request form (http://quod.lib.umich.edu/e/ebm/request form.php) helped automate the process of responding to customer inquiries and orders. The Library also developed an extensive FAQ document (http://www.lib.umich.edu/espresso-bookmachine/espresso-book-machine-university-michigan-library-questions-and-answers) in response to the many questions and information requests received from others interested in Michigan's experience.

All services offered are limited to items that are in the public domain, fall under Section 108 of the U.S. Copyright Code, or have the permission of the rights holder to print. Within these parameters, the Library currently is using the machine to print the following:

- Books from the Library's local digitized holdings

- Google books from the EspressNet catalog

- Books for units within the Library, either for reference or research, or gifts and samples to visitors and colleagues

- Titles for the Library's collection, whether as replacement copies or as new additions

- Books for other campus units, such as a history of the School of Social Work produced as gifts for an emeritus faculty event, and a book about medical education in the U.S., printed for the Dean of the University of Michigan Medical School to give as holiday gifts to department chairs

- Books for classroom or lab use, such as works of literature, lab notes, or facultyauthored text books

- Advance review copies of forthcoming titles for the University of Michigan Press

- Student output, such as an anthology of poetry and short stories from the Shapiro Library's annual Café Shapiro event, and a new journal created by graduate students from the School of Social Work

- Titles from MPublishing's recently-launched University of Michigan Faculty Reprints service (http://www.lib.umich.edu/spo/facultyreprints.html), which helps current and former faculty put their out-of-print books back into circulation via print on demand and online access.

In addition to the current services, the Library is poised to begin the following:

- A collaboration with a local independent press to print short runs of the works of poetry and fiction it publishes, with the hope of beginning a consortium for small presses in Southeast Michigan and campus-related poetry publishers 
- Printing theses and dissertations for their authors

- Printing in-copyright titles from the EspressNet catalog

- Self-publishing for local campus and community authors.

Other services under consideration include the printing of course packs (assuming no copyright restrictions), specialty series (Library treasures; classics; subject-themed), and books for local businesses and organizations, such as commemorative volumes or corporate histories.

There is no requirement that a customer be affiliated with the University of Michigan in order to use the machine, but EBM books are not shipped, so the customer must be able to pick up the book in person. Based on anecdotal observation, the majority of the EBM requests appear to be from students, particularly graduate students. Titles requested in support of classroom work and research seem to be the main focus. In terms of popular subject matter, the categories vary widely, which is of course one of the advantages of combining deep catalogs of digital content with a print on demand, point of sale machine. Commonly requested subjects include chemistry, physics, mathematics, reports of exploration, religion, and literature.

Self-publishing has turned out to be a highly-requested service, and forms the bulk of the EBM revenue stream for many owners. The appeal is undeniable, and the University of Michigan itself has had quite a few requests and inquiries for such a service. On Demand Books has been developing a self-publishing software "tool kit" that EBM owners can employ to streamline and automate this process, including the ability for customers to upload their book file directly to the machine, and a cover generator feature that would allow customers to easily design and layout a cover for their book, automatically sized to the correct dimensions. However, the tool kit has not yet been formally released, so the Library has decided to finalize its initial plans for an internally-developed self-publishing service.

Based on Michigan's experience, some basic considerations for any academic institution thinking about purchasing an EBM may include:

- Machine operation and maintenance (who will be the main operator? Who will be the backup operator, if any? Who will order supplies and make calls for service? What will be the hours of operation? Where will the machine be physically located? Is there someone with programming or technical skills who can work with the EspressNet API, troubleshoot problems, and access the server log files?)

- Order processing and customer service (how will customers convey their order requests? Who will process and track those requests? Who will create book block and cover files when needed? Who will respond to EBM-related inquiries, questions, and concerns? How will customers pay for their books? Will payment be collected before or after the books are printed? Who will handle questions about an item's copyright status?)

- Services (what services will be offered, both now and in the future? How will those services be priced? Who will be involved in actually developing and implementing those services? To whom will those services be offered? Will orders be shipped, or will sales be limited to local customers?) 
- Marketing and outreach (how will the machine and services be advertised? How will customers discover which titles can be ordered? How can faculty and students be made aware of the machine's capabilities in connection with their work?)

This list is not exhaustive, and is not meant to imply that all of these issues will be pertinent to every EBM owner, particularly with the new versions of the machines, nor that the University of Michigan has addressed them all to its satisfaction.

\section{Marriott Library's EBM Experience at the University of Utah}

Last March, Rick Anderson, Associate Director for Scholarly Resources \& Collections at the Marriott Library at the University of Utah, published an article describing their library's experience with the Espresso Book Machine ${ }^{\circledR}$ (Anderson, 2010). Some interesting parallels with Michigan's experience include, as he describes it, "a 'ready-fire-aim' approach" (Anderson, 2010, p. 39), the excitement and awe evoked in those seeing the machine in operation for the first time, and an emphasis on providing patron access to any book needed. They too have experienced some glitches and hiccups with EBM performance, even with the newer version of the machine.

Like the University of Michigan, the University of Utah has integrated their university press into the Library's organizational and reporting structure; similarly, the Marriott Library is using their EBM to print Press books. However, in Michigan's case, the Press's advance review copies are being printed, while at Utah, the intention is to print their Press's out-of-print backlist titles for local users.

Unlike the University of Michigan Library, the Marriott Library has adopted a formal collection development policy of moving toward a patron-driven acquisitions model. As Anderson explains, having an Espresso Book Machine on site will allow the Library to supplement electronic access to content by quickly supplying print copies only when needed or requested, rather than trying to anticipate demand. They plan to offer patrons the option to purchase the EBM copy outright, or lend the newly-printed title to the patron and place it in the stacks upon return (Anderson, 2010). One would imagine that many university libraries will follow the Marriott Library's experience in this venture with great interest, as it could provide compelling evidence for more widespread adoption of such a model elsewhere.

\section{Pros and Cons}

Like most anything else, the Espresso Book Machine ${ }^{\circledR}$ is one of those technologies that is wonderful when it works correctly, and extremely frustrating when it doesn't. After running smoothly for weeks, the machine may suddenly act up, often at the least opportune timeswhen performing a demonstration for a group of visitors, for example, or when several large orders are pending. Most of the problems involve the cover not aligning correctly with the book block, difficulty clamping smaller books, crooked trim, or incorrect trim sizes. Printer problems can halt production, calling for temporary or permanent printer replacement. 
Probably the biggest drawback, however, is its lack of a user-friendly catalog interface or discovery mechanism. The EspressNet catalog from On Demand Books was slower to develop than anticipated, so the UM Library built its own catalog by accretion; as titles were requested from the digital collections, the resulting book block and cover PDFs entered the local catalog and could then be reprinted easily upon future request. The Library initially populated the catalog with approximately 20 titles, some of them best sellers from the print on demand program already in place, and some of local interest about the University of Michigan, the state of Michigan, or the Great Lakes. Samples were printed to distribute at the annual Library Donor Reception in September 2008, and sales to the campus and local community began soon after. The local catalog has since grown to more than 300 titles.

On Demand Books has released an API to its EspressNet catalog, so that each location can modify and customize the software to provide its own version of public access to the EspressNet catalog. Search results by default are limited to a single page of 20 results, and the lack of consistent and reliable metadata associated with the EspressNet catalog entries, in particular with the public domain Google book titles, means search and retrieval is rather haphazard and limited. ODB is aware of these problems and is working both internally and with Google to make improvements.

In an effort to aid discoverability and enhance the ordering process, the programmer who works with the EBM at Michigan is developing a method to populate the Library's local OPAC, Mirlyn, with links to purchase available titles on the Espresso Book Machine ${ }^{\circledR}$. This will give patrons another option for accessing the book in addition to the current choices of checking out a print copy of the title, or reading it online (if not protected by copyright).

It is to be expected that there will be some growing pains and bumps in the road along the way, both for the creators and distributors of the new technology and the users, but the rewards of having a book-making machine are also great. For a library, the ability to get a book into a patron's hands when no copy may exist in the physical collection, and to provide that copy quickly and inexpensively, certainly seems a worthy service. The University of Michigan's prominent participation in Google's mass digitization project has prompted some concern that the Library no longer values the print book, or is trying to "do away with" its physical collections altogether. While there may be a [very] long-range shift toward more digital books and fewer physical copies, access to the information itself will always be paramount. The combination of digitization efforts and ownership of an Espresso Book Machine ${ }^{\circledR}$ allows a sort of fluid movement from print to digital and back to print, and from born-digital to print. It gives the Library the ability to produce different formats to suit different needs. The EBM network allows the Library to make its content available to other EBM locations around the world, while concurrently giving local customers the ability to purchase from other content providers copies of books that the University itself may not hold.

\section{Future Developments}

One of the pitfalls of being an early adopter of any new technology is that very often, what was cutting edge one week becomes outdated the next, as subsequent generations of the product 
are developed and released to market. As mentioned earlier, the version 1.5 EBM was more of a prototype machine, and underwent a fairly extensive transformation from version 1.5 to version 2.0 (now version 2.2). The version 2 machines are much smaller, much quieter, and books now travel a vertical path through the machine rather than horizontal. The color cover printer is now inkjet rather than laser, and resides within the machine itself rather than being external.

Another major change is the choice of book block printers and vendor; in addition to the Kyocera printer that comes with the machines marketed and sold by On Demand Books, customers now have the option of purchasing a Xerox $4112^{\mathrm{TM}}$ printer instead. ODB and Xerox have been building a complementary relationship, which began in January of 2010 with an announcement that Xerox printers would power the EBMs and the two companies would jointly market and sell the machines.[5] Beginning in the first quarter of 2011, the Xerox corporation will begin selling and servicing their own versions of the machine, built by On Demand Books and equipped with Xerox's $4112^{\text {TM }}$ black and white printer.[6] The Xerox solution offers a fast, high-quality printer and the strength of the Xerox reputation. The company plans to offer both lease and purchase options, and intends to provide more extensive support for EBM owners-both in training them in the technical aspects of the machine, and in helping them build and market a profitable print on demand service. On Demand Books has stated that version 2.2 is the "go to market" machine on which they will be focusing their sales and marketing attention for the foreseeable future, so no major changes to the machines will be introduced for some time.

The EBM operators as a group have been more than willing to share their trials, tribulations, and advice with each other, which is of tremendous benefit, particularly for new operators or those experiencing a particular problem for the first time. Almost invariably, the problem has been experienced by at least one other location, and usually a solution has been figured out that can be passed on to others. In addition, On Demand Books holds monthly virtual users group meetings via online chat and audio sessions to keep EBM owners and operators abreast of current developments, future plans, technical fixes, and the like, and to address questions and concerns from the group.

\section{Conclusion}

Response to the Library's machine has been overwhelmingly positive and has generated much interest from many different segments, particularly other university libraries. The machine's main strengths include the ability to produce high-quality books quickly, inexpensively, and with the flexibility to easily change, update, or customize content. Being able to assist campus departments, faculty, and students with printing special projects, books for classroom use, or general research material is exciting and gratifying, and the UM Library looks forward to continued development and expansion of its book-printing services. 


\section{References}

Anderson, R. (2010), "The Espresso Book Machine: The Marriott Library Experience", Serials: The Journal for the Serials Community, Vol. 23 No. 1, pp. 39-42.

\section{Notes}

1. On Demand Books (2010), www.ondemandbooks.com/our ebm locations.htm (accessed 7 November 2010).

2. On Demand Books (2010), www.ondemandbooks.com/faq.htm\#1 (accessed 23 September 2010).

3. Severance, C. (2010), personal communication.

4. Although a Mac operating system is standard on the EBMs, the Library decided to use a Linux machine instead. This way updates could be integrated into the process already in place for other machines under Core Services' oversight. This will change with the version 2.2 machine however, as it cannot operate with a Linux system.

5. On Demand Books (2010), "Xerox Technology to Fuel Espresso Book Machine; Worldwide Agreement Includes Global Marketing and Sales Support", available at: www.ondemandbooks.com/Xerox-ODB\%20NR.pdf (accessed 10 November 2010).

6. Xerox Corporation (2010), “Xerox Puts Book Publishing Power in Consumers' Hands; Expands Market for the Espresso Book Machine", available at: http://news.xerox.com/pr/xerox/xeroxexpands-book-publishing-with-Espresso-Book-Machine.aspx (accessed 10 November 2010). 